\title{
Influência do país de origem e a relação entre imagem de preço, valor percebido e intenção de recompra de vinhos finos
}

\section{Influence of the country of origin and the relationship between price image, perceived value and intention to repurchase fine wines}

\author{
FERNANDA RIZZON CORREIO \\ UCS - Universidade de Caxias do Sul \\ ANA PAULA GRACIOLA CORREIO \\ UCS - Universidade de Caxias do Sul \\ DEONIR DE TONI CORREIO \\ UCS - Universidade de Caxias do Sul \\ GABRIEL SPERANDIO MILAN CORREIO \\ Cesf - Centro de Ensino Superior Cenecista de Farroupilha
}

\section{RESUMO}

Este estudo teve por objetivo verificar a relação entre a imagem de preço e o valor percebido e os impactos do valor percebido sobre a intenção de recompra de vinhos finos, nacionais e importados. As hipóteses, a partir do framework teórico proposto, foram testadas através de uma survey, com amostra final de 259 consumidores de vinhos finos. Os resultados encontrados mostram que a imagem de preço apresenta impacto sobre o valor percebido, assim como, o valor percebido afeta a intenção de recompra. As principais contribuições teóricas deste estudo se referem a abordagem da imagem de preço e do valor percebido como antecedentes da intenção de recompra e do efeito país de origem como moderador dessas relações. Como contribuições práticas, este estudo amplia o conhecimento aos gestores para melhorar suas estratégias de precificação, compreender a percepção dos consumidores com relação ao valor percebido e a intenção de recompra e, assim, conduzir as empresas a melhores práticas gerenciais.

Palavras-chave: Imagem de Preço. Valor Percebido. Intenção de Recompra. Vinho Fino Nacional. Vinho Fino Importado. 


\section{Abstract}

The purpose of this study was to verify the relationship between the price image and the perceived value and the impacts of the perceived value on the intention to repurchase fine, national and imported wines. The hypotheses, based on the proposed theoretical framework, were tested through a survey, with a final sample of 259 consumers of fine wines. The results showed that the price image has an impact on the perceived value, as well as, the perceived value affects the repurchase intention. The main theoretical contributions of this study refer to the image of price and perceived value as antecedents of the repurchase intention and the country of origin effect as moderator of these relations. As a practical contribution, this study extends the knowledge to managers to improve their pricing strategies, understand consumers' perceptions of perceived value and repurchase intent, and thus drive companies to better management practices.

Keywords: Price Image. Perceived Value. Repurchase Intent. National Fine Wine. Fine Wine Imported.

\section{INTRODUÇÃo}

O efeito país de origem diz respeito à influência das informações e percepções formadas sobre a origem de um produto nas atitudes e no comportamento de compra e/ou consumo em relação a um produto ou marca (ALMEIDA; DROUVOT, 2009). A imagem do país de origem pode ajudar a diferenciar os produtos e assim, impactar a intenção de compra dos consumidores (LEE; LOCKSHIN, 2012).

Na última década o mercado mundial vitivinícola passou por profundas transformações com o aumento da produção e do número de países produtores, acompanhadas de uma gradativa queda no consumo per capita. Assim sendo, a busca por mercados externos tornou-se imperativa para a sobrevivência das empresas devido à pressão da concorrência no mercado interno e ao aumento dos competidores externos atuantes no país (ZEN; DALMORO; FENSTERSEIFER, 2009), o que torna relevante o estudo do efeito país de origem para os vinhos finos.

Neste contexto de competitividade, estudiosos evidenciaram a relevância de se estudar a imagem, pois ela auxilia na compreensão do comportamento do consumidor que repercute na intenção de compra 
e no comportamento de consumo (STERN; ZINKHAN; JAJU, 2001; ORSI; CAPPELLOZZA; VIEIRA, 2018). Assim, a imagem de preço é conceituada como uma variável latente multidimensional que se consiste de um conjunto de dimensões perceptivas sobre as atividades de fixação de preços e suas consequências (ZIELKE, 2006). O preço é uma variável capaz de influenciar o julgamento do consumidor em relação a produtos e marcas, estabelecer as circunstâncias entre o comprador e o vendedor e quão dispostos estes estão para efetivarem uma troca (RAO; MONROE, 1989). Essa percepção remete ao conceito de valor percebido, que pode ser conceituado como o equilíbrio na relação de troca entre os benefícios recebidos (produto ou serviço) e sacrifícios oferecidos (custos de aquisição). É o que se espera com a compra de determinado produto ou serviço e o que é recebido em troca pelo que é dado pelo consumidor (ZEITHAML, 1988; CHI; KILDUFF, 2011).

A imagem de preço está ligada ao desenvolvimento do valor percebido de tal modo que, ao aumentar o valor dessa variável, cresce também à percepção de valor e a intenção de compra (DE TONI; MAZZON, 2013). Oliver (2010) conceitua um tipo especial de intenção de compra, a intenção de recompra, sendo essa a probabilidade de o consumidor repetir a compra de um produto ou serviço. A intenção de recompra refere-se às respostas geradas pelo cliente com base em um processo de avaliação individual do produto que afeta suas intenções futuras (CHEN, 2011).

As percepções de preço são uma parte da imagem da empresa que ajudam a identificar discrepâncias entre o posicionamento de preço almejado e as percepções dos consumidores. Portanto, analisar a imagem de preço é importante para monitorar os efeitos das mudanças nas táticas e estratégias de preço da empresa perante os clientes (ZIELKE, 2006; SANEMATSU; SILVA; VIEIRA, 2016). Outro aspecto a ser considerado é a multidimensionalidade da imagem de preço, onde as empresas poderão identificar qual ou quais dimensões devem ser agregadas as suas estratégias de precificação visando melhor desempenho (ZIELKE, 2010). Por conseguinte, pesquisas relacionadas à imagem de preço de produto são relevantes, pois permitem um entendimento de como o preço impacta na percepção de valor e nas intenções de compra dos consumidores e devido a sua importância para as empresas, uma vez que as mesmas utilizam o preço como um indicador de resultado. 
Do mesmo modo, o resultado da avaliação do produto, gerado a partir das experiências anteriores do consumidor com o produto, relaciona-se com as intenções de recomprá-lo (HAN; KIM, 2009). Uma vez que a intenção de recompra está relacionada à lucratividade e rentabilidade das empresas, ela se torna um dos principais objetivos de qualquer negócio. Assim, estudos na área de marketing têm dado maior ênfase a intenção de recompra e seus determinantes (RAZAVI; SAFARI; SHAFIE, 2012).

Pesquisas anteriores mencionam que é necessário o desenvolvimento de novos estudos tendo como construto a intenção de recompra e seus antecedentes (LIN; LEKHAWIPAT, 2014) o que justifica a construção teórica e prática que se buscou desenvolver neste estudo. Nesta pesquisa foram abordados como construtos antecedentes da intenção de recompra a imagem de preço (ZIELKE, 2006; 2010) e o valor percebido (ZEITHAML, 1988), além do efeito moderador do país de origem na relação entre a imagem de preço e o valor percebido e na relação entre o valor percebido e a intenção de recompra. Portanto, este trabalho objetiva verificar a relação entre a imagem de preço e o valor percebido e os impactos do valor percebido sobre a intenção de recompra de vinhos finos, nacionais e importados. Além desta sessão introdutória, será apresentado o referencial teórico como suporte às hipóteses testadas, o método e as análises dos resultados. Por fim, as contribuições deste estudo.

\section{FRAMEWORK TEÓRICO}

\subsection{Imagem de preço}

Zielke $(2006$; 2011) define a imagem de preço como uma variável latente multidimensional composta por crenças e sentimentos subjetivos. De Toni e Mazzon (2013) corroboram com estes conceitos e afirmam que a imagem de preço envolve um construto multidimensional formado por conjuntos de representações, impressões, convicções e redes de significados que estão depositados na memória de cada indivíduo. Para Zielke (2011), essa multidimensionalidade está refletida nas dimensões funcional, emocional, simbólica, de justiça, axiomática e social da percepção do preço como construtos antecedentes do valor percebido do produto e da consequente intenção de compra. 
Neste sentido, Monroe (1990) e Avlonitis e Indounas (2006) corroboram a ideia de que a percepção de preço de um produto é um objeto de estudo complexo, multidisciplinar e multidimensional que reúne conhecimentos da psicologia cognitiva e social, da economia, do marketing e de outras áreas do conhecimento. Nesta pesquisa serão abordados como componentes da imagem de preço definidos a priori: o nível de preço, a justiça de preço, a qualidade e a dimensão simbólica, conforme apontado por Scopel (2014) e sintetizado na Figura 1.

Figura1 - Dimensões da imagem de preço

\begin{tabular}{|l|l|}
\hline $\begin{array}{l}\text { Dimensões da Ima- } \\
\text { gem de Preço }\end{array}$ & Conceito \\
\hline $\begin{array}{l}\text { Nível de Preço } \\
\text { Zielke (2006; 2010) }\end{array}$ & $\begin{array}{l}\text { Entendimento dos preços praticados, sem levar em } \\
\text { consideração as diferenças de qualidade e utilidade } \\
\text { dos produtos e marcas. Refere-se à quantidade de } \\
\text { dinheiro que os consumidores precisam desembolsar } \\
\text { para obter o produto ou serviço. }\end{array}$ \\
\hline $\begin{array}{l}\text { Justiça de Preço } \\
\text { Huangfu e Zhu }\end{array}$ & $\begin{array}{l}\text { Relacionada à percepção de benefício e sacrifício } \\
\text { quanto ao preço proposto pelas empresas. Depende } \\
\text { da funcionalidade do produto em gerar satisfação, } \\
\text { da reputação da empresa, da imagem simbólica da } \\
\text { marca, entre outros fatores. }\end{array}$ \\
\hline $\begin{array}{l}\text { Qualidade } \\
\text { Geithaml, Bitner e }\end{array}$ & $\begin{array}{l}\text { Consumidores utilizam o preço como indicador de } \\
\text { qualidade relacionando o nível de qualidade do } \\
\text { produto ao seu nível de preço, reduzindo o risco } \\
\text { percebido. "É caro, mas é bom". }\end{array}$ \\
\hline $\begin{array}{l}\text { Dimensão Simbólica } \\
\text { Stern, Zinkhan e Jaju } \\
\text { (2001) }\end{array}$ & $\begin{array}{l}\text { Consumidores compram produtos não somente pelo } \\
\text { que eles podem fazer, mas principalmente pelo que } \\
\text { significam. Inserção social do consumidor. }\end{array}$ \\
\hline
\end{tabular}

Fonte: Elaborada pelos autores conforme literatura.

\subsection{Valor percebido}

Conforme Zeithaml (1988) e Sweeney e Soutar (2001), o valor é configurado a partir da percepção do benefício (qualidade) e do sacrifício (preço) no processo de compra e consumo de um bem ou serviço. Há um forte componente sociopsicológico que depende de como o consumidor percebe a relação entre custos e benefícios mo- 
netários e não monetários (NAGLE; HOLDEN, 2003; MUNNUKKA, 2006). Assim, o valor percebido é o principal esteio que sustenta os relacionamentos existentes entre uma empresa e seus clientes, representa o que o cliente entende como valioso para o início e para a manutenção de um relacionamento duradouro com um fornecedor (RUST; ZEITHAML; LEMON, 2000).

Quando se aborda a imagem relativa ao preço, na ótica do consumidor, não se pode ignorar sua relação com o valor percebido. A percepção de valor de ofertas pelos consumidores tem recebido atenção dos estudiosos de marketing como sendo um aspecto determinante no processo de decisão de compra (ZEITHAML, 1988; SHETH; NEWMAN; GROSS, 1991; BOLTON; DREW, 1991). Tomando por base os pressupostos teóricos expostos, a primeira hipótese a ser testada nesta pesquisa é apresentada:

H1: A imagem de preço impacta positivamente o valor percebido.

\subsection{Intenção de recompra}

A intenção de recompra foi apresentada como a resposta gerada pelo consumidor após realizar a avaliação geral do produto levando em conta suas intenções futuras de negociar novamente com a empresa (SRIVASTAVA; SHARMA, 2013). A intenção de recompra tornou-se cada vez mais importante para os gestores de marketing, visto que, sua compreensão a partir do comportamento do consumidor tem implicações econômico-financeiras para as empresas (KEININGHAM et al., 2015). Complementam Le \& Supphellen (2017), que afirmam que a lucratividade e a rentabilidade das empresas podem aumentar substancialmente quando os clientes optam pelo mesmo fornecedor, de forma recorrente, em uma perspectiva de longo prazo. Em contraponto, se os clientes optarem por trocar de fornecedor haverá perda de receitas futuras para a empresa além de custos associados à aquisição de novos clientes.

Conforme Voss, Parasuraman e Grewal (1998) e Caruana, Money e Berthon (2000) o valor percebido é o mais importante indicador da intenção de recompra. O relacionamento entre empresa e cliente é sustentado pelo valor, se o cliente não percebe valor no que a empresa lhe oferece, as estratégias de marca e retenção não serão 
efetivas na construção do relacionamento (RUST; ZEITHAML; LEMON, 2001). A construção do valor para o cliente é o fundamento de todas as atividades de troca relacional (WU et al., 2014) e é um fator crítico de influência para a recompra dos clientes (CHIU; WANG; FANG; HUANG, 2014). Sendo assim, propõe-se a segunda hipótese de pesquisa:

H2: O valor percebido impacta positivamente a intenção de recompra.

\subsection{Efeito moderador do país de origem}

A imagem do país de origem normalmente reflete a percepção geral do consumidor sobre a qualidade dos produtos de um determinado país e a avaliação global deste produto (KNIGHT; CALANTONE, 2000; HÁ-BROOKSHIRE, 2012). Zdravkovic (2013) afirma que o país de origem influencia sobremaneira o julgamento do produto, sendo que, este julgamento é moderado pelo tipo de informação sobre o produto (informação positiva, negativa ou falta de informação).

A imagem do país de origem pode ser definida como o estereótipo que os consumidores atribuem aos produtos de um país, que é criado por variáveis como, por exemplo, as características nacionais e o seu contexto social, econômico, político, histórico e cultural (SILVA; LAZZARI; MILAN; EBERLE, 2015). Rezvani et al. (2012) ressaltam que o consumidor se preocupa com a origem do produto e considera a informação do país de origem um fator que indica o seu nível de qualidade. Os consumidores podem usar a imagem de certo país em avaliações de produtos quando eles são incapazes de detectar a verdadeira qualidade deste produto antes da compra (HONG; WYER Jr., 1989). Sendo assim, pode-se construir a terceira hipótese:

H3a: Se a origem do vinho for nacional, então a relação entre a imagem de preço e o valor percebido será mais fraca.

H3b: Se a origem do vinho for nacional, então a relação entre o valor percebido e a intenção de recompra ser mais fraca.

H3c: Se a origem do vinho for nacional, então a relação entre os construtos formadores da imagem de preço será mais fraca. Se a 
origem do vinho for importada, então a relação entre os construtos formadores da imagem de preço será mais forte.

\subsection{Modelo proposto}

O modelo proposto, segue as relações teóricas sugeridas pela literatura. A Figura 2 representa a síntese das hipóteses delineadas anteriormente.

\section{Figura 2 - Framework teórico proposto}

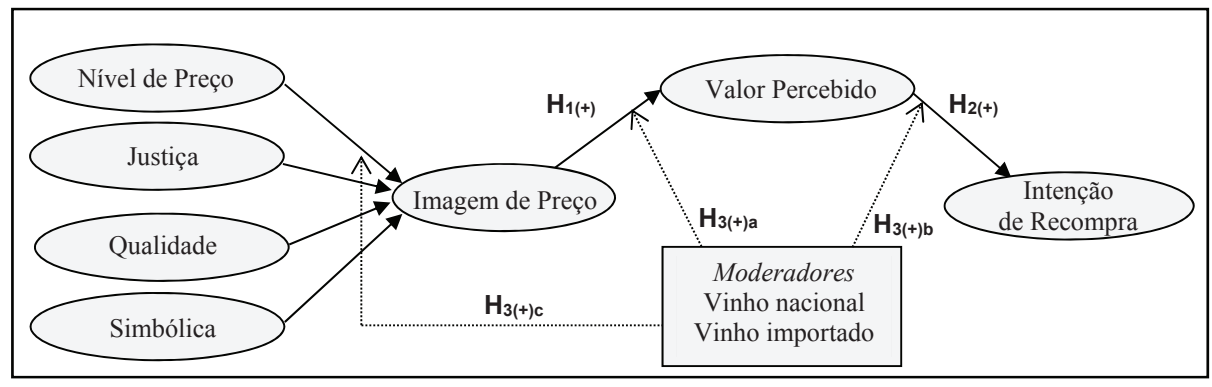

Fonte: Elaborada pelos autores conforme teoria.

\section{MÉTOdo}

Pesquisa de natureza quantitativa-descritiva (HAIR Jr. et al., 2014; MALHOTRA; BIRKS; WILLS, 2012), implementada através da aplicação de uma survey de corte transversal (FOWLER Jr., 2009; HAIR Jr. et al., 2014). Foi utilizada a modelagem de equações estruturais (MEE) para a realização das análises dos dados (BYRNE, 2010; KLINE, 2011) com base na Análise Fatorial Confirmatória (AFC) e na Análise de Caminhos (Path Analysis) (HAIR Jr. et al., 2014).

A operacionalização da escala e seus respectivos indicadores foram definidos através da utilização da escala do tipo Likert de sete pontos, que compreende os extremos de "1. Discordo Totalmente" a "7. Concordo Totalmente" (BEARDEN et al., 2011). Foram utilizadas escalas já validadas em estudos anteriores, conforme as Tabelas 1 e 2. Após a elaboração e estruturação do questionário de pesquisa foi realizada a validação de conteúdo e a validação de face (KINNEAR; TAYLOR, 1996), sendo o questionário submetido às análises de dois experts da área. A coleta dos dados foi realizada no período de janeiro a março de 2016 através do método de autopreenchimento (FINK, 2013).

\section{RESUltados}


Os respondentes foram selecionados por conveniência (MALHOTRA; BIRKS; WILLS, 2012) e a amostra é composta por $74(27,4 \%)$ consumidores de supermercados, $47(17,4 \%)$ alunos do curso de graduação em administração de uma universidade, 96 (35,6\%) respondentes on-line e $53(19,6 \%)$ consumidores de uma loja de cosméticos, totalizando 270 respondentes. Deste total, 141 (53,8\%) respondentes eram do gênero masculino e 121 (46,2\%) do gênero feminino. Dos 270 respondentes, $62(11,5 \%)$ apresentaram idade superior a 50 anos, 43 $(8 \%)$ dos respondentes com idade entre 31 à 35 anos, $45(8,3 \%)$ entre 26 à 30 anos, $24(4,4 \%)$ entre 21 à 25 anos e $7(1,3 \%)$ entre 18 à 20 anos.

Para participar desta pesquisa foi definida como restrição que os participantes fossem consumidores tanto de vinhos finos nacionais quanto de vinhos finos importados. Foi constatado que os consumidores estão dispostos a pagar mais por vinhos finos importados, com $100(37,03 \%)$ dos respondentes dispostos a pagar de $\mathrm{R} \$ 31,00$ à 40,00 por garrafa de $750 \mathrm{ml}$. Para os vinhos finos nacionais foi verificado que $95(35,13 \%)$ dos respondentes estão dispostos a pagar de $\mathrm{R} \$ 21,00$ à 30,00 por garrafa de $750 \mathrm{ml}$ em cada compra.

Em decorrência da falta de consistência foram eliminados nove questionários que apresentaram mais de $10 \%$ de não-resposta (missing data), resultando em uma amostra de 261 respondentes (522 casos). Em relação as observações atípicas, na verificação dos outliers, através do $Z$ scores (análises univariadas) foram eliminados dois respondentes (4 casos - questionários 6, 153, 276, 423) e, através da verificação de análises multivariadas, com o teste da distância de Mahalanobis $\left(\mathrm{D}^{2}\right)$, nenhum caso foi excluído. Ao final destes testes, 259 respondentes (518 casos) foram considerados válidos (HAIR Jr. et al., 2014; KLINE, 2011). No teste de normalidade foram encontrados valores dentro do permitido para a curtose (kurtosis) $(-1,447$ à 2,839$)$ e assimetria (skewness) $(-1,801$ à 0,702$)$. Para o teste da homoscedasticidade $\mathrm{o}$ valor foi significante $(p<0,000)$ no teste $\mathrm{M}$ de Box (HAIR Jr. et al., 2014). As Tabelas 1 e 2 apresentam as análises dos construtos em estudo. 


\section{Tabela 1 - Análise Fatorial Confirmatória dos}

Construtos Formadores da Imagem de Preço

\begin{tabular}{|c|c|c|c|c|c|}
\hline Construtos & Média & $\begin{array}{l}\text { Desvio } \\
\text { Padrão }\end{array}$ & Estimativa & $\mathrm{CC}$ & AVE \\
\hline \multicolumn{6}{|l|}{ Nível de Preço $(\alpha=0,866)$} \\
\hline IP1 - O preço do vinho fino é muito baixo & 3,22 & 1,72 & 0,832 & \multirow{6}{*}{0,846} & \multirow{6}{*}{0,585} \\
\hline IP2 - Vinho fino é um produto barato. & 3,20 & 1,76 & 0,856 & & \\
\hline $\begin{array}{l}\text { IP3 - O preço do vinho fino é menor em compa- } \\
\text { ração com outras bebidas. }\end{array}$ & 3,89 & 1,96 & 0,549 & & \\
\hline IP4 - Vinho fino é um produto de preço baixo. & 3,22 & 1,75 & 0,783 & & \\
\hline IP5 - O preço do vinho fino é muito alto * & 3,35 & 1,70 & 0,645 & & \\
\hline IP6 - Vinho fino é um produto caro * & 3,30 & 1,70 & 0,652 & & \\
\hline \multicolumn{6}{|l|}{ Justiça $(\alpha=0,885)$} \\
\hline $\begin{array}{l}\text { JU1 - O vinho fino está sendo vendido a um } \\
\text { preço justo. }\end{array}$ & 4,07 & 1,73 & 0,818 & \multirow{4}{*}{0,887} & \multirow{4}{*}{0,663} \\
\hline $\begin{array}{l}\text { JU2 - O vinho fino está sendo vendido a um } \\
\text { preço aceitável. }\end{array}$ & 4,29 & 1,57 & 0,870 & & \\
\hline JU3 - O preço do vinho fino se justifica. & 4,48 & 1,72 & 0,743 & & \\
\hline JU4 - O vinho fino é vendido a um preço razoável. & 4,34 & 1,57 & 0,822 & & \\
\hline \multicolumn{6}{|l|}{ Qualidade $(\alpha=0,807)$} \\
\hline QL1 - O vinho fino tem uma boa qualidade. & 5,91 & 1,21 & 0,861 & \multirow{4}{*}{0,816} & \multirow{4}{*}{0,539} \\
\hline $\begin{array}{l}\text { QL2 - A qualidade do vinho fino é perfeitamente } \\
\text { aceitável. }\end{array}$ & 5,72 & 1,20 & 0,874 & & \\
\hline $\begin{array}{l}\text { QL3 - A qualidade do vinho fino é melhor em } \\
\text { comparação com outras bebidas. }\end{array}$ & 5,40 & 1,59 & 0,474 & & \\
\hline $\begin{array}{l}\text { QL4 - Vinho fino é um produto de alta qualida- } \\
\text { de. }\end{array}$ & 5,69 & 1,36 & 0,654 & & \\
\hline \multicolumn{6}{|l|}{ Dimensão Simbólica $(\alpha=0,927)$} \\
\hline $\begin{array}{l}\text { DS1 - O vinho fino vai fazer com que eu me } \\
\text { sinta mais poderoso. }\end{array}$ & 4,12 & 2,20 & 0,672 & \multirow{4}{*}{0,931} & \multirow{4}{*}{0,775} \\
\hline $\begin{array}{l}\text { DS2 - O vinho fino me possibilitará uma posição } \\
\text { de destaque na sociedade. }\end{array}$ & 3,05 & 2,13 & 0,922 & & \\
\hline $\begin{array}{l}\text { DS3 - O vinho fino irá contribuir para aumentar } \\
\text { meu status. }\end{array}$ & 2,88 & 2,09 & 0,983 & & \\
\hline $\begin{array}{l}\text { DS4 - O vinho fino irá melhorar de forma favo- } \\
\text { rável a percepção de outras pessoas em relação a } \\
\text { minha pessoa. }\end{array}$ & 2,93 & 2,07 & 0,913 & & \\
\hline
\end{tabular}

Fonte: Elaborada pelos autores conforme dados da pesquisa. Nota. $\left(^{*}\right)$ Variável Reversa 
Para cada construto (Tabelas 1 e 2) foram realizadas as verificações de consistência interna (Cronbach's alpha), a estimativa (estimate), confiabilidade composta (CC) e variância extraída (AVE), como sugerem Fornell e Larcker (1981). Os valores de alfa encontrados estão acima de 0.60, conforme recomendado pela literatura (MALHOTRA; BIRKS; WILLS, 2012; HAIR Jr. et al., 2014).

\section{Tabela 2 - Análise Fatorial Confirmatória do Valor \\ Percebido e da Intenção de Recompra}

\begin{tabular}{|c|c|c|c|c|c|}
\hline Construtos & Média & $\begin{array}{l}\text { Desvio } \\
\text { Padrão }\end{array}$ & Estimativa & $\mathrm{CC}$ & AVE \\
\hline \multicolumn{6}{|l|}{ Valor Percebido $(\alpha=0,696)$} \\
\hline $\begin{array}{l}\text { VP1 - Os benefícios oferecidos pelo } \\
\text { vinho fino são compatíveis com os } \\
\text { sacrifícios para obtê-lo. }\end{array}$ & 4,83 & 1,70 & 0,614 & \multirow{3}{*}{0,701} & \multirow{3}{*}{0,444} \\
\hline $\begin{array}{l}\text { VP2 - O vinho fino oferece um bom } \\
\text { valor para o dinheiro. }\end{array}$ & 4,78 & 1,56 & 0,774 & & \\
\hline VP3 - O vinho fino vale o seu preço. & 4,94 & 1,65 & 0,591 & & \\
\hline \multicolumn{6}{|l|}{ Intenção de Recompra $(\alpha=0,865)$} \\
\hline $\begin{array}{l}\text { IR1 - Irei consumir vinhos finos nova- } \\
\text { mente. }\end{array}$ & 6,19 & 1,30 & 0,551 & \multirow{5}{*}{0,869} & \multirow{5}{*}{0,577} \\
\hline $\begin{array}{l}\text { IR2 - Comprarei maiores quantidades } \\
\text { de vinhos finos nos próximos anos. }\end{array}$ & 4,94 & 1,87 & 0,827 & & \\
\hline $\begin{array}{l}\text { IR3 - Considerarei vinhos finos como } \\
\text { minha primeira opção de compra em } \\
\text { relação a outras bebidas }\end{array}$ & 4,54 & 2,08 & 0,706 & & \\
\hline $\begin{array}{l}\text { IR4 - Eu pretendo aumentar o volume } \\
\text { do consumo de vinhos finos }\end{array}$ & 4,39 & 2,06 & 0,906 & & \\
\hline $\begin{array}{l}\text { IR5 - Encorajarei amigos, vizinhos e/ } \\
\text { ou parentes a comprar e a consumir } \\
\text { vinhos finos }\end{array}$ & 4,36 & 2,12 & 0,759 & & \\
\hline
\end{tabular}

Fonte: Elaborada pelos autores conforme dados da pesquisa.

Para verificar a validade discriminante foi utilizado o método de Fornell e Larcker (1981), com o intuito de confirmar se a variância extraída de cada construto é maior que a variância compartilhada, através das correlações ao quadrado com os demais construtos em estudo, conforme a Tabela 3. 
Tabela 3 - Teste de Fornell e Larcker (1981)

para Validade Discriminante

\begin{tabular}{lllllll}
\hline Construtos & JU & QL & DS & IP & VP & IR \\
1. Justiça Preço & 0,66 & & & & & \\
2. Qualidade & 0,36 & 0,54 & & & & \\
3. Dimensão Simbólica & 0,19 & 0,19 & $\mathbf{0 , 7 8}$ & & & \\
4. Nível de Preço & 0,59 & 0,16 & 0,11 & $\mathbf{0 , 5 8}$ & & \\
5. Valor Percebido & 0,69 & 0,53 & 0,14 & 0,50 & $\mathbf{0 , 3 8}$ & \\
6. Intenção de Recompra & 0,29 & 0,47 & 0,20 & 0,19 & 0,464 & $\mathbf{0 , 5 8}$ \\
\hline
\end{tabular}

Fonte: Elaborada pelos autores conforme dados da pesquisa.

A validação do modelo estrutural tem por base a MEE através do método de Máxima Verossimilhança (ML - Miximum Likelihood) para verificar o ajuste dos construtos e a qualidade destes ajustes através dos índices (GOF - Goodness of Fit) que compreende o GFI, RMSEA, AGFI, TLI, NFI e CFI, tanto para o modelo geral quanto para o modelo moderado pelo tipo de vinho fino, nacional e importado. Foi constatado que o ajuste dos modelos pode ser considerado satisfatório (HAIR Jr. et al., 2014; BAGOZZI; YI, 2012) conforme Tabela 4.

Tabela 4 - Índices de Ajuste do Modelo Geral e dos Modelos Moderados

\begin{tabular}{llll}
\hline Índice de Ajuste & Índice de Ajuste & Modelo Geral & $\begin{array}{l}\text { Moderado } \\
\text { (vinho } \\
\text { nacional e } \\
\text { importado) }\end{array}$ \\
Absoluto & GFI & 0,867 & 0,841 \\
Absoluto & AGFI & 0,837 & 0,807 \\
Incremental & NFI & 0,885 & 0,858 \\
Incremental & TLI & 0,902 & 0,908 \\
Incremental & CFI & 0,913 & 0,918 \\
Absoluto & RMSEA & 0,071 & 0,047 \\
\hline
\end{tabular}

Fonte: Elaborada pelos autores conforme dados da pesquisa. 
Os índices apresentados (Tabela 4) estão de acordo com os valores exigidos pela literatura (HAIR Jr. et al., 2014; KLINE, 2011; BAGOZZI; YI, 2012), o GFI e AGFI apresentaram valores próximos ao nível de fronteira $(\mathrm{p}<0,000 ; \mathrm{GFI}=0,867$; $\mathrm{AGFI}=0,837$; NFI $=$ $0,885 ; \mathrm{TLI}=0,902 ; \mathrm{CFI}=0,913$; $\mathrm{RMSEA}=0,070)$, levemente abaixo de 0,900. Para Bagozzi e Yi (2012) estes valores não invalidam um bom encaixe do modelo.

A imagem de preço em segunda ordem, em conjunto com o valor percebido, determina as intenções de recompra dos consumidores. Com relação ao poder de explicação do modelo teórico proposto pode-se considerar um moderado e/ou baixo poder de explicação $\left(\mathrm{R}^{2}\right.$ =0,17), mas para Pilati e Laros (2007), estes valores são aceitáveis ao se considerar dimensões comportamentais. Portanto, a intenção de recompra é explicada por $17 \%$ dos construtos antecessores no modelo proposto, o valor percebido e a imagem de preço.

Quanto ao modelo geral foi possível constatar que a percepção de Justiça de Preço (JU) foi o construto de segunda ordem que apresentou maior poder de explicação para a imagem de preço com $75 \%\left(R^{2}=0,748\right)$, seguida pelo Nível de Preço (IP) com $43 \%$ $\left(R^{2}=0,425\right)$, na sequência a percepção de qualidade com $18 \%\left(R^{2}=\right.$ $0,179)$ e a dimensão simbólica com poder de explicação de $4 \%\left(R^{2}\right.$ $=0,042)$. Foi possível constatar que $79 \%\left(R^{2}=0,791\right)$ da explicação do Valor Percebido (VP) decorre da imagem de preço. Na Tabela 5 são apresentados os coeficientes de explicação $\left(R^{2}\right)$ e a moderação para os diferentes tipos de vinho nas relações em estudo.

Tabela 5 - Poder de Explicação $\left(R^{2}\right)$ do modelo geral e do modelo moderado

\begin{tabular}{l|l|l|l|l}
\hline \multirow{2}{*}{$\mathrm{Hi}$} & \multirow{2}{*}{ Relacionamentos Causais } & $\begin{array}{l}\text { MODELO } \\
\text { GERAL }\end{array}$ & $\begin{array}{l}\text { VINHO NACIO- } \\
\text { NAL }\end{array}$ & $\begin{array}{l}\text { VINHO IMPOR- } \\
\text { TADO }\end{array}$ \\
\cline { 3 - 5 } & & $\mathrm{R}^{2}$ & $\mathrm{R}^{2}$ & $\mathrm{R}^{2}$ \\
\hline & Imagem de Preço $\leftarrow \mathrm{JU}$ & 0,748 & 0,669 & 0,869 \\
\hline & Imagem de Preço $\leftarrow \mathrm{QL}$ & 0,179 & 0,367 & 0,043 \\
\hline & Imagem de Preço $\leftarrow \mathrm{DS}$ & 0,042 & 0,109 & 0,010 \\
\hline & Imagem de Preço $\leftarrow \mathrm{IP}$ & 0,425 & 0,414 & 0,437 \\
\hline $\mathbf{H}_{1}$ & Imagem de Preço $\leftarrow \mathrm{VP}$ & 0,791 & 0,932 & 0,612 \\
\hline $\mathbf{H}_{2}$ & $\mathrm{VP} \rightarrow \mathrm{IR}$ & 0,173 & 0,197 & 0,173 \\
\hline
\end{tabular}

Fonte: Elaborada pelos autores conforme dados da pesquisa. 
Conforme a Tabela 5, a Justiça de Preço (JU) explica de forma diferente a imagem de preço no modelo moderado, ou seja, para o vinho fino importado o poder de explicação é maior (87\%) em comparação ao vinho fino nacional (67\%). A Qualidade (37\%) para o vinho fino nacional possui maior poder de explicação da imagem em comparação ao vinho fino importado (4\%). A Dimensão Simbólica possui poder de explicação diferente para o vinho fino nacional (11\%) em relação ao vinho fino importado (1\%). O Nível de Preço (IP), tanto para o vinho fino nacional quanto para o vinho fino importado, apresentou poder de explicação próximo (42\%vinho nacional; $44 \%$ vinho importado). O valor percebido, tanto para o vinho fino nacional quanto para o vinho fino importado apresentou valores próximos (20\%vinho nacional; $17 \%$ vinho importado). No entanto, é importante destacar que a imagem de preço possui poder de explicação para o valor percebido do vinho fino nacional superior (93\%) em comparação ao vinho fino importado (61\%).

Um fato importante a se destacar referente as hipóteses, na Tabela 6, é a não significância (sem impacto) da dimensão simbólica sobre a imagem de preço para os vinhos finos importados, através da rejeição deste construto que compõe a imagem de preço $(\beta=0,147$, $p=0,155)$. Ao passo que a dimensão simbólica para o vinho nacional $(\beta=0,453, p=0,000)$ apresentou significância (impacto) sobre a imagem de preço. Na Tabela 5 foi possível constatar que a dimensão simbólica possui poder de explicação de $10 \%$ da imagem de preço para os vinhos finos nacionais, ao passo que, para os vinhos finos importados, a dimensão simbólica explica apenas 1\% da imagem de preço. Na Tabela 6 são apresentadas as hipóteses, tanto para o modelo geral quanto para o modelo moderado, assim como, o teste $Z$ de moderação em relação ao tipo de vinho. 
Tabela 6 - Testes das hipóteses do modelo geral e do modelo moderado

\begin{tabular}{|c|c|c|c|c|c|c|c|c|c|}
\hline \multirow[b]{2}{*}{$\mathrm{Hi}$} & \multirow[t]{2}{*}{ Relacionamentos Causais } & \multicolumn{2}{|c|}{ Modelo Geral } & \multicolumn{2}{|c|}{ VINHO NACIONAL } & \multicolumn{2}{|c|}{$\begin{array}{l}\text { VINHO IMPOR- } \\
\text { TADO }\end{array}$} & \multirow{2}{*}{\multicolumn{2}{|c|}{$\begin{array}{l}\text { MODERAÇÃO DOS } \\
\text { TIPOS DE VINHO } \\
\text { Teste Z }\end{array}$}} \\
\hline & & Estimate & $\mathrm{Hi}$ & Estimate & $\mathrm{Hi}$ & Estimate & $\mathrm{Hi}$ & & \\
\hline & Imagem-Preço $\leftarrow J P$ & $1,220^{*}$ & Suporta & $1,142^{*}$ & Suporta & $1,327^{*}$ & Suporta & 1,176 & Não sig. \\
\hline & Imagem-Preço $\leftarrow \mathrm{QL}$ & $0,442^{*}$ & Suporta & $0,718^{*}$ & Suporta & $0,179^{*}$ & Suporta & $-5,021$ & Significante \\
\hline & Imagem-Preço $\leftarrow \mathrm{DS}$ & $0,294^{*}$ & Suporta & $0,453^{*}$ & Suporta & 0,147 & Rejeita & $-2,138$ & Significante \\
\hline & Imagem-Preço $\leftarrow$ IP & $0,654^{*}$ & Suporta & $0,602^{*}$ & Suporta & $0,693^{*}$ & Suporta & 0,707 & Não sig. \\
\hline $\mathrm{H}_{1}$ & Imagem-Preço $\leftarrow V P$ & $0,706^{*}$ & Suporta & $0,843^{*}$ & Suporta & $0,525^{*}$ & Suporta & $-2,021$ & Significante \\
\hline $\mathrm{H}_{2}$ & $\mathrm{VP} \rightarrow \mathrm{IR}$ & $0,382^{*}$ & Suporta & $0,381^{*}$ & Suporta & $0,438^{*}$ & Suporta & 0,416 & Não sig. \\
\hline
\end{tabular}

Fonte: Elaborada pelos autores conforme dados da pesquisa.

$$
\text { Nota. }+p<.10,{ }^{*} p<.001
$$

Com base na Tabela 6, para o modelo geral, as relações entre a Imagem de Preço, Valor Percebido e Intenção de Recompra apresentaram relações significantes com um $p$-valor $<0,001$. Sendo que os $\beta$ foram de 0,706 (Imagem de preço $\rightarrow$ Valor Percebido) e 0,382 (Valor Percebido $\rightarrow$ Intenção de Recompra), resultados que confirmam H1 e H2. A imagem de preço, na perspectiva do consumidor, predispõe um acréscimo na intenção de compra e uma maior rentabilidade para a organização (CROSS; DIXIT, 2005). Deste modo, a imagem de preço está ligada ao desenvolvimento do valor percebido pelo cliente de tal modo que, ao aumentar o valor dessa variável, cresce também a percepção de valor e a intenção de compra (DE TONI; MAZZON, 2013).

Para Sheth, Newman e Gross (1991) a decisão de compra baseia-se em uma rede complexa de valores, em que diferentes dimensões da percepção de valor se manifestam com ênfases diferentes, em distintas situações e tais dimensões de valor são independentes. Para Monroe (1990) a relação entre o preço e a percepção de valor do produto para o consumidor é que determina a decisão de compra.

Assim, o valor percebido do produto é visto como um fator que influencia a decisão de compra dos consumidores dado que eles usam a informação de preço como unidade de mensuração de valor em seus processamentos mentais de escolha de um produto (ZEITHAML, 1988; BOLTON; DREW, 1991; MITTAL et al., 2007). A 
imagem de preço de produto centrada nas expectativas do consumidor tende a proporcionar um aumento na intenção de compra e na rentabilidade dos produtos comercializados (CROSS; DIXIT, 2005), portanto, melhorias na imagem de preço de um produto estão associadas a incrementos no valor desse produto para o consumidor.

Conforme Voss, Parasuraman e Grewal (1998) e Caruana, Money e Berthon (2000) o valor percebido é o mais importante indicador da intenção de recompra. O relacionamento entre empresa e cliente é sustentado pelo valor, se o cliente não percebe valor no que a empresa lhe oferece, as estratégias de marca e retenção não serão efetivas na construção do relacionamento (RUST; ZEITHAML; LEMON, 2001). A construção do valor para o cliente é o fundamento de todas as atividades de troca relacional (WU et al., 2014) e é um fator crítico de influência para a recompra dos clientes (CHIU et al., 2014).

Referente ao teste de moderação, na Tabela 6, os tipos de vinho fino (nacional e importado) são abordados como moderadores das relações em estudo. Sobel (1982) coloca que o valor para o escore-z (critical ratio for difference) acima ou abaixo de $+/-1,96, \mathrm{p}<0,05$, indica a existência do efeito indireto da variável, nesse caso, o tipo de vinho. Portanto, três relações apresentaram diferenças significativas com relação ao tipo de vinho (Imagem de Preço $\leftarrow$ Qualidade; Imagem de Preço $\leftarrow$ Dimensão Simbólica; Imagem de Preço $\rightarrow$ Valor Percebido). Assim, é possível compreender que a qualidade e a dimensão simbólica, construtos formadores da imagem de preço são afetados pelos moderadores desta relação (vinho fino nacional e importado). Além disso, a relação entre a imagem de preço e o valor percebido é compreendida de forma diferente entre consumidores do vinho fino nacional e do vinho fino importado, suportando a H3a: Se a origem do vinho for nacional, então a relação entre a imagem de preço e o valor percebido será mais fraca.

\section{Considerações Finais}

O objetivo de pesquisa proposto foi “Verificar a relação entre a imagem de preço e o valor percebido e os impactos do valor percebido sobre a intenção de recompra de vinhos finos, nacionais e importados". Conforme os resultados obtidos e com as hipóteses confirmadas e rejeitadas, conclui-se que a imagem de preço tem 
um importante efeito positivo no valor percebido, suportando a primeira hipótese (H1). Esses achados vão ao encontro da literatura que afirma que uma imagem de preço positiva influencia o valor percebido, quando o consumidor passa a inferir qualidade e benefícios superiores a partir do preço do produto em relação as ofertas concorrentes (ZEITHAML, 1988).

A segunda hipótese de pesquisa $\mathrm{H} 2$ : o valor percebido tem um efeito positivo na intenção de recompra também foi confirmada. Isto significa que quanto maior for a percepção de valor para o consumidor, maior será sua intenção de recomprar. A literatura suporta essa afirmação quando traz que, para que o cliente tenha intenção de recomprar é preciso que ele perceba valor no produto que a empresa está oferecendo. Para Voss, Parasuraman e Grewal (1998), o valor percebido é o mais importante indicador da intenção de recomprar.

A presente pesquisa possui contribuições para a teoria de marketing. A primeira contribuição teórica se refere ao aprofundamento do estudo sobre as dimensões que formam a imagem de preço em segunda ordem para o contexto dos vinhos finos, ampliando os achados de Scopel (2014) e Schuler e De Toni (2015). A segunda contribuição teórica foi a construção e o teste empírico do modelo estrutural proposto, que englobou as relações entre a imagem de preço, o valor percebido e a intenção de recompra, além da moderação do modelo através do efeito país de origem (vinho fino nacional e vinho fino importado).

Este estudo pode motivar futuras pesquisas para o aprofundamento destes temas. Pesquisas anteriores mencionam que é necessário o desenvolvimento de novos estudos tendo como construto a intenção de recompra e seus antecedentes (LIN; LEKHAWIPAT, 2014) o que justifica a construção teórica e prática que se buscou desenvolver neste estudo. Nesta pesquisa foram abordados como construtos antecedentes da intenção de recompra, a imagem de preço de produto (ZIELKE, 2006; 2010) e o valor percebido (ZEITHAML, 1988).

Para o modelo geral, todas as relações foram confirmadas, tanto as formadoras da imagem de preço quanto as demais relações em estudo. No entanto, foi constatado que a dimensão simbólica não impactou na formação da imagem de preço dos vinhos finos 
importados no modelo moderado. A partir disso, é possível inferir que os vinhos finos importados não carregam tanto a ideia de poder, status e percepção da posição social a outras pessoas, ao ponto que o coeficiente de explicação apenas explicou um por cento do modelo. Com isso, pode-se compreender que o vinho fino nacional carrega mais a questão simbólica que os vinhos finos importados, o que contradiz os resultados de pesquisas anteriores que trazem que produtos importados exercem maior percepção simbólica sobre os consumidores (MARTIN; EROGLU, 1993). Como a pesquisa concentrou-se na região da Serra Gaúcha, onde a produção de vinhos tem forte impacto econômico, social e cultural, o vinho fino nacional mostrou-se ser mais valorizado (ROESE, 2008).

Com relação ao coeficiente de explicação para o modelo geral e para o modelo moderado é possível destacar alguns achados importantes. $\mathrm{O}$ valor percebido possui maior poder de explicação através da imagem de preço para os vinhos finos nacionais (93\%) em comparação com os vinhos finos importados (61\%). Como contribuição gerencial deste estudo sugere-se que as vinícolas nacionais deem mais atenção à imagem de preço para melhorar a percepção de valor dos consumidores com relação aos seus vinhos e que utilizem este mecanismo de valor percebido como meio para barrar e/ou minimizar o impacto dos produtos importados em seu mercado de atuação.

Neste estudo a justiça de preço foi o construto que mais explicou a imagem de preço. Foi possível constatar que os consumidores percebem maior justiça na compra de vinhos finos importados $(87 \%)$ em comparação aos vinhos finos nacionais (67\%). No entanto, ambos os índices de justiça são significativos para explicar a imagem de preço. O nível de preço foi o segundo construto que mais explicou a imagem de preço, tanto para os vinhos finos nacionais quanto para os importados. A qualidade, formadora da imagem de preço, apresentou maior explicação para a imagem de preço dos vinhos finos nacionais. Isso posto, é possível constatar uma preocupação dos consumidores com a qualidade na compra dos produtos nacionais, ao passo que, a qualidade para os produtos importados não apresentou grande explicação da imagem de preço, corroborando os achados de Grant (1991) e Roese (2008) que afirmam que a qualidade está relacionada à reputação da empresa e a imagem do local de produção. 
Neste estudo a imagem de preço e o valor percebido possuem um poder de explicação sobre a intenção de recompra de $17 \%$ para o modelo geral. Este índice pode ser considerado moderado e/ou baixo, mas aceitável devido à mensuração de dimensões comportamentais (PILATI; LAROS, 2007). Logo, através deste estudo é possível perceber um gap de pesquisa na busca por compreender quais construtos, além da imagem de preço e do valor percebido, poderão explicar a intenção de recompra.

O modelo teórico proposto, desenvolvido e testado neste estudo contribui com possíveis direcionamentos e sugestões aos gestores de empresas vitivinícolas para suas estratégias de marketing e de gestão. O presente estudo identificou de que forma o consumidor avalia os vinhos finos em relação a sua imagem de preço, valor percebido e intenção de recompra. Determinar como os consumidores de vinhos percebem estes aspectos no produto é importante para a estratégia das empresas e para a melhoria da sua competitividade. Isso proporciona aos gestores, a possibilidade de identificar os aspectos que necessitam de atenção e a elaboração de estratégias que satisfaçam o consumidor, garantindo relacionamentos de longo prazo entre as empresas e seus clientes.

Quando o cliente percebe valor na oferta oferecida pela empresa ele tende a recomprar. Isto é o que o cliente espera, que a empresa entregue valor compatível com os preços praticados. Se o cliente percebe valor na oferta da empresa, irá recomprar e a recompra por parte dos clientes é fundamental para que a empresa se mantenha atuante no mercado e possa projetar seu crescimento a curto, médio e longo prazo. Fabricantes e comerciantes de vinhos finos devem estar atentos ao mercado, buscando conquistar novos consumidores a todo momento; comunicando os diferenciais do seu produto, qualidade e valor podem conquistar novos consumidores e também manter os clientes já fidelizados.

Apesar do cuidado metodológico no desenvolvimento desta pesquisa, este estudo apresenta algumas limitações. Como limitações de pesquisa, foi constatado que o valor para a AVE do construto Valor Percebido se apresentou na linha de fronteira $(0,444)$. Como sugestões de futuras pesquisas foi observada a necessidade de replicação desta escala para outros contextos, contribuindo para melhorar a 
compreensão da imagem de preço e suas relações. Outra sugestão é a ampliação de pesquisas que abordem a intenção de recompra dos consumidores e também outros construtos, tais como, o impacto da imagem de preço sobre o conhecimento da marca, força da marca e países específicos em um contexto de país de origem.

\section{REFERÊNCIAS}

ALMEIDA, F. C.; DROUVOT, H. (2009). O efeito do país de origem de produtos na percepção de executivos franceses e brasileiros. Gestão \& Regionalidade, v. 25, n. 74, p. 48-68, 2009.

AVLONITIS, G. G.; INDOUNAS, K. A. Pricing practices of service organizations. Journal of Service Marketing, v. 20, n. 5, p. 346-356, 2006. http://dx.doi.org/10.1108/08876040610679954.

BAGOZZI, R. P.; YI, Y. Specification, evaluation, and interpretation of structural equation models. Journal of the Academy of Marketing Science, v. 40, n. 1, p. 8-34, 2012. http://dx.doi:10.1007/ s11747-011-0278-x.

BOLTON, R. N.; DREW, J. H. A multi-stage model of customers' assessments of service quality and value. Journal of Consumer Research, v. 17, n. 4, p. 375-384, 1991.

CARUANA, A.; MONEY, A.; BERTHON, P. Service quality and satisfaction - the moderating role of value. European Journal of Marketing, v. 34, ns. 11/12, p. 1338-1356, 2000.

CHEN, Y. Effect of the travel website design quality, design characteristics, and shopping value on online consumer purchase intention. Journal of E-Business, v. 13, n. 3, p. 673-696, 2011.

CHI, T.; KILDUFF, P. P. D. Understanding consumer perceived value of casual sport wear: an empirical study. Journal of Retailing and Consumer Services, v. 18, n. 5, p. 422-429, 2011.

CHIU, C-M.; WANG, E. T. G.; FANG, Y-H.; HUANG, H-Y. Understanding customers' repeat purchase intentions in $\mathrm{B} 2 \mathrm{C}$ e-commerce: the roles of utilitarian value, hedonic value and perceived risk. Information Systems Journal, v. 24, n. 1, p. 85-114, 2014.

CROSS, R. G.; DIXIT, A. Customer-centric pricing: the surprising secret for profitability. Business Horizons, Amsterdam, v. 48, n. 6, p. 483-491, 2005.

DE TONI, D.; MAZZON, J. A. Imagem de preço de produto: proposição de um modelo conceitual. RAUSP - Revista de Administração. v. 48, n. 3, p. 454-468, 2013. http://dx.doi:10.5700/ rausp1099.

FINK, A. How to conduct surveys: a step-by-step guide. 5. ed. Thousand Oaks: Sage Publications, 2013.

FORNELL, C.; LARCKER, D. F. Evaluating structural equation models with unobservable variables and measurement error. Journal of Marketing Research, v. 18, n. 1, p. 39-50, 1981.

FOWLER Jr., F. J. Survey research methods. 4. ed. Thousand Oaks: Sage Publications, 2009.

GRANT, R. M. The resource-based theory of competitive advantage. California Management Review, v. 33, n. 3, p. 114-135, 1991. 
HAIR Jr., J. F.; WOLFINBARGER, M.; ORTINAU, D. J.; BUSH, R. P. Fundamentos de pesquisa de marketing (3. ed.) Porto Alegre: Bookman, 2014.

HAN, H.; KIM, W. Outcomes of relational benefits: restaurant customers' perspective. Journal of Travel \& Tourism Marketing, v. 26, n. 8, p. 820-835, 2009.

HONG, S. T.; WYER Jr., R. S. Country of origin attributes and product evaluations the effects of time delay between information and judgments. Journal of Consumer Research, v. 17, p. 277-288, 1990.

HUANGFU, G.; ZHU, L. Do consumers' perceptions of price fairness differ according to type of firm ownership? Social Behavior And Personality, v. 40, n. 4, p. 693-698, 2012

KEININGHAM, T. L.; FRENNEA, C. M.; AKSOY, L.; BUOYE, A.; MITTAL, V. A five-component customer commitment model: implications for repurchase intentions in goods and services industries. Journal of Service Research, v. 18, n. 4, p. 433-450, 2015.

KINNEAR, T. C.; TAYLOR, J. R. Marketing research: An applied approach. 5. ed. New York: McGraw-Hill, 1996.

KLINE, R. B. Principles and Practice of Structural Equation Modeling. The Guilford Press. New York: London, 2011.

KNIGHT, G. A.; CALANTONE, R. J. A flexible model of consumer country of origin perceptions: a cross cultural investigation. International Marketing Review, v. 17, n. 2, p. 127-137, 2000.

LE, N. Q.; SUPPHELLEN, M. Determinants of repurchase intentions of real estate agent services: direct and indirect effects of perceived ethicality. Journal of Retailing and Consumer Services, v. 35, p. 84-90, 2017.

LEE; R.; LOCKSHIN, L. Reverse country of origin effects of product perceptions destination image. Journal of Travel Research, v. 51, n. 4, p. 502-511, 2012.

LIN, C.; LEKHAWIPAT, W. Factors affecting online repurchase intention. Industrial Management \& Data Systems, v. 114, n. 4, p. 597-611, 2014.

MALHOTRA, N. K.; BIRKS, D.; WILLS, P. Marketing research: applied approach (4. ed.). New York: Pearson, 2012.

MARTIN, I. M.; EROGLU, S. Measuring a multi-dimensional construct: country image. Journal of Business Research, v. 8, n. 3, p. 191-210, 1993.

MONROE, K. B. Pricing: making profitable decisions. 2 ed. New York: McGraw-Hill, 1990.

MUNNUKKA, J. Pricing method as a tool for improved price perception. Journal of Revenue and Pricing Management, Wellington, v. 5, n. 3, p. 207-220, 2006.

NAGLE, T.; HOLDEN, R. K. Estratégias e táticas de preços: um guia para as decisões lucrativas. São Paulo: Prentice Hall, 2003.

OLIVER, R. L. Satisfaction: a behavioral perspective on the consumer. 2 ed. New York: Irwin/ McGraw-Hill, 2010.

ORSI, D. F. O.; CAPPELlOZZA, A.; VIEIRA, A. M. Práticas de Consumo Colaborativo na Cidade de São Paulo: Um Estudo nos Estratos Econômicos A e B. Revista de Inovação e Sustentabilidade, v. 9, n. 3, p. 109-121, 2018. 
PILATI, R.; LAROS, J. A. Modelos de equações estruturais em psicologia: conceitos e aplicações. Psicologia: teoria e pesquisa, v. 23, n. 2, p. 205-216, 2007.

RAO, A. R.; MONROE, K. B. The effect of price, brand name, and store name on buyers' perceptions of product quality: An integrative review. Journal of marketing Research, p. 351-357, 1989.

RAZAVI, S. M.; SAFARI, H.; SHAFIE, H. Relationships among service quality, customer satisfaction and customer perceived value: evidence from iran's software industry. Journal of Management and Strategy, v. 3, n. 3, p. 28, 2012.

REZVANI, S.; DEHKORDI, G. J.; RAHMAN, M. S.; FOULADIVANDA, F.; HABIBI, M.; EGHTEBASI, S. A conceptual study on the country of origin effect on consumer purchase intention. Asian Social Science, v. 8, n. 12, p. 205-215, 2012.

ROESE, M. O Mondovino de cabeça para baixo: as transformações no Mercado internacional do vinho e o novo empresariado vinícola. Revista Sociologia Política, v. 16, n. 31, p. 71-83, 2008.

RUST, R. T.; ZEITHAML, V. A.; LEMON, K. N. Driving customer equity: how customer lifetime value is reshaping corporate strategy. New York: The Free Press, 2000.

SANEMATSU, L.; SILVA, A.; VIEIRA, A. Relação entre Fabricante e Varejista: um Estudo Qualitativo Comparativo no Setor de Peças Automotivas. NAVUS - Revista de Gestão e Tecnologia, v. 6, n. 3, p. 56-69, 2016.

SCHULER, M.; DE TONI, D. Gestão da imagem de organizações, marcas e produtos através do MCI: Método para Configuração de Imagem. São Paulo: Editora Atlas, 2015.

SCOPEL, A. E. M. Efeito dos níveis de preço de uma nova marca de produto sobre a imagem de preço, 2014. Dissertação (Mestrado em Administração) - Universidade de Caxias do Sul, Caxias do Sul, 2014.

SHETH, J. N.; NEWMAN, B. I.; GROSS, B. L. Why we buy what we buy: a theory of consumption values. Journal of Business Research, v. 22, n. 2, 159-170, 1991.

SOBEL, M. Asymptotic intervals for indirect effects in structural equations models. In: Leinhart, S. (Ed.). Sociological methodology. San Francisco: Jossey-Bass, p. 290-312, 1982.

SRIVASTAVA, K.; SHARMA, N. K. Service quality, corporate brand image, and switching behavior: the mediating role of customer satisfaction and repurchase intention. Services Marketing Quarterly, v. 34, n. 4, p. 274-291, 2013.

STERN, B.; ZINKHAN, G. M.; JAJU, A. Marketing images: construct definition, measurement issue, and theory development. Marketing Theory, London, v. 1, n. 2, p. 201-224, Dec. 2001.

SWEENEY, J. C.; SOUTAR, G. N. Consumer perceived value: the development of a multiple item scale. Journal of Retailing, Amsterdan, v. 77, n. 2, p. 203-220, 2001.

VOSS, G. B.; PARASURAMAN, A.; GREWAL, D. The role of price, performance, and expectations in determining satisfaction in service exchanges. Journal of Marketing, v. 62, p. 46-62, 1998.

WU, L.; CHEN, K.; CHEN, P.; CHENG, S. Perceived value, transaction cost, and repurchase-intention in online shopping: a relational exchange perspective. Journal of Business Research, v. 67, p. $2768-2776,2014$. 
ZDRAVKOVIC, S. Does country-of-origin matter to generation Y? Young Consumers, v. 14, n. 1, p. 89-102, 2013.

ZEITHAML, V. A. Consumer Perceptions of Price, Quality, and Value: A Means End Model and Synthesis of Evidence. Journal of Marketing, v. 52, n. 3, p. 2-22, 1988.

ZEITHAML, V. A.; BITNER, M. J.; GREMLER, D. D. Marketing de serviços: a empresa em foco no cliente. 5. ed. Porto Alegre: Bookman, 2011.

ZEN, A. C.; DALMORO, M.; FENSTERSEIFER, J. E. O Desenvolvimento de Recursos em Redes Interorganizacionais e o Processo de Internacionalização: o caso Wines from Brazil. In: Encontro da ANPAD, XXXIII, São Paulo, set. 2009. Anais. Rio de Janeiro: ANPAD, 2009.

ZIELKE, S. Measurement of Retailers' Price Images with a Multiple-item Scale. The International Review of Retail, Distribution and Consumer Research, v. 16, n. 3, p. 297-316, 2006.

ZIELKE, S. How price image dimensions influence shopping intentions for different store formats. European Journal of Marketing, United Kingdom, v. 44, n. 6, p. 748-770, 2010.

ZIELKE, S. Integrating Emotions in the Analysis of Retail Price Images. Psychology \& Marketing, v. 28, n. 4, p. 330-359, 2011.

Recebido em: 18-3-2019

Aprovado em: 16-11-2020

Avaliado pelo sistema double blind review.

Editor: Coordenação do PPGA/UMESP

Disponível em http://mjs.metodista.br/index.php/roc 